larity of this structure with the small spines on the arm of Hapalemur induced me to examine the adjacent smooth patch on the forearm of Lemur catta, and I had the satisfaction of finding a large collection of glands, the secretion from which, when dried, gives rise to the horny projection in question.

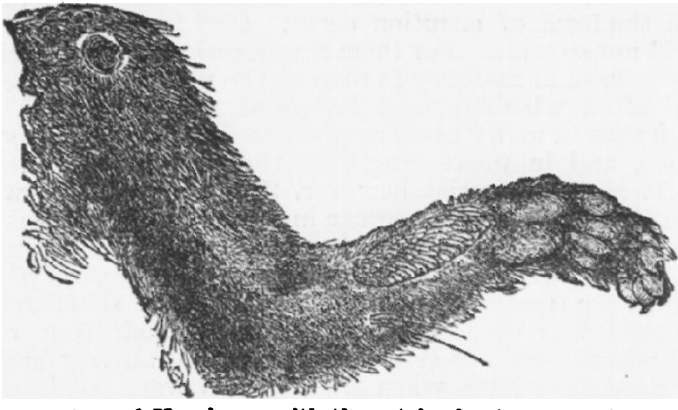

Fig. 11.-Arm of Hapalemur with the patch of cutaneous spines on its forearm ('roc. Zool. Soc.)

These structures are interesting, inasmuch as they may be regarded as intermediate to the pathological cutaneous horn on the one hand, and the cutaneous nasal horn of the rhinoceros on the other. They also furnish some light as to the nature of the singular patch of hard integument known as the castor on the inside of the foreleg of the horse. In addition, we may use them as physiological types of cutaneous horns which in man only occur under pathological conditions.

\section{ON THE ABORTIVE TREATMENT OF} SYPHILIS.

Read before the Medical Society of Iondon, on Monday, February
$20 t h, 1 S S s$.

By JONATHAN HUTCHINSON, F.R.S., F.R.C.S., LL.D., Emeritus Professor of Surgery at the London Hospital.

Fon many years past I have been in the habit of assuring patients who came to me with indurated chancres but without any other symptoms, that they would in all probability wholly escape the secondary stage. As years have gone on I have found myself holding out this hope with increasing confldence. My treatment has been almost uniform, and has consisted in giving mercury in the form of grey powder in one-grain doses three times a day, at least, and more frequently if the symptoms did not quickly yield. I have always told the patient that he must take these pills for sir months at least. The results have also been very uniform, or have varied chiefly according to the period of the disease at which the treatment was begun. The effect of the medicine in softening the induration is usually quite evident within a week, and may be expected to be complete in the course of a month or a little more. After this the patient remains without symptoms till the end of the course, except, perhaps, some slight persisting enlargement of the inguinal glands. At the end of the six months, if the treatment is left off, there not very infrequently follows in three weeks or a month an erythematous general eruption. This eruption is never serere, never becomes papular or scaly, and always vanishes in a few days if the mercury is resumed. It is never attended by failure of health, and but rarely by sore throat. On account of its frequency after six months' courses, I have lately been in the habit of continuing the treatment for nine or twelve months, and am willing to admit that it might be wise to continue it for still longer periods. As regards relapses at still longer periods, I must state that, in a certain proportion of cases, sores in the moutl or scaly patches in the palms, or a liability to transitory erythemata on the skin have occurred, but they have generally been in connection with some special kind of irritation.

The statement which I wish to make quite clear is this: that I believe that it is quite possible, by the early and continuous use of mercury, to suppress the secondary stage-in other words, to make it abortive. In exceedingly few cases where it has been possible to use mercury without interruption in this way have I known a well characterised secondary eruption or a typical sore throat to occur. In cases where diarrhoes or sudden ptyalism have caused the course to be interrupted, the success has been less complete; but where the potient is careful, and can bear the drug, I may ropeat that I believe that it is easily possible to prevent secondary symptoms. This assertion is not by any means the same as saying that it is possible to cure syphilis, for it does not concern itself with the tertiary stage. It is desirable, I think, in order that we should arrive at sound conclusions, that we should take our problem in parts. In making the proposition which I desire to submit to you this evening, that mercury is a specific antidote for the syphilitic virus, and that by its use the disease may be made abortive, I will divide my argument into several parts.

The first statement shall be one with which all will agree. It is this: that in cases in which induration is well characterised and considerable, it always yields quickly and definitely to the influence of mercury. The very rare apparent exceptions to this which we witness occur to those who in a peculiar manner resist the influence of mercury. We never see sores remain typically hard when the patient is under the influence of mercury.

The next is that in cases in which high temperatures have been observed in syphilis they always abate under the influence of mercury.

Thirdly, I beliere that all will agree that when a patient receives no treatment until his eruption is well out, the use of mercury will usually in the most definite manner cause the erup tion to disappear. There is but little less certainty about this than there is as to the disappearance of induration in the sore, and the exceptions occur only when the treatment disagrees, and has to be interrupted.

If these several propositions be true, if mercury always causes induration when present to soften down, fever when present to subside, and an eruption when present to disappear, I cannot think that any will see much improbability in the assertion that if used before the fever, rash, etc., have shown themselres, and steadily continued, it will prevent their development. It would be extraordinary if these symptoms should develop de novo under the very conditions which all but invariably secure their removal when extant.

Those who object to the statement that mercury is an antidote to syphilis, and decline to employ such terms as " specific," "abortive treatment " and the like, do so because, as they allege with truth, it can seldom or never be asserted that the disease has been wholly or, at any rate, permanently cured. This is, however, I cannot but think, putting a too strong meaning on the words. It may easily be the fact that we have not yet hit upon the best method of using the remedy 80 as to secure permanent results. It is not fair to demand of a "specific" that it shall always prove its efficacy without regard to differences in the mode in which it is employed. A remedy may be fairly called "specific" if it always and invariably manifests its power over the phenomena of a disease. It is for the prescriber to find out how so to use his specific as to bring about an actual cure. As regards the term "abortive treatment," its appropriateness may surely be justified in any case in which it is designed to cut short the development of a malady and prevent the evolution of its natural stages. We must not strain the word to make it mean absolute annihilation of the thing concerned. If a scheme of treatment of syphilis, begun in the primary stage, is planned to prevent the secondary phenomena, and usually does so, it may, I think, be fairly styled "abortive" in contradistinction with others which make no pretence to prevent the ordinary evolution of the malady. Abortion, as regards preventing tertiary symptoms, is, as I shall endeavour to show immediately, another matter. It is possible that in our present modes of use of mercury we neither begin early enough nor continue long enough to secure that result.

The term antidote, when used in reference to mercury as against syphilis, must be sustained by resort to more hypothetical reasoning as to the nature of the disense. In the year 1860 , in a paper read before the Hunterian Society, I first ventured to claim a place for syphilis amongst the exanthemata, and argued that in its phenomena as regards stages, period of incubation, and other points, it resembled the diseases which we attribute to specific animal poisons. Amongst those who took part in the debate on my paper were Mr. Acton, Mr. De Méric, and others who at that time were the leading authorities on the subject. Some years later I read before the same Society another paper, claiming for mercury, on much the same grounds that I have this evening advanced, the position of a specific. My views were on each occa- 
sion warmly opposed, but 1 believe that the progress of investigation since then has done much to facilitate their acceptance. For myself, I may say that 1 have always, in speculating about the cause and evolution of syphilis, held firmly to the belief that it is due to a specific particulate virus, just as small-pox is, or in the language of to-day, to a living microbe. Other observers, with most praiseworthy zeal and industry, have occupied themselves with the endeavour to bring this microbe to actual demonstration, nor have I the slightest doubt that their search will some day be crowned with success. In the meantime, if we would understand the disease we must, I think, take its existence as granted. It is in reference to this as yet hypothetical microbe, that we justify the assertion that mercury is an antidote; we know how powerful that drug is in preventing the derelopment of plant life, and that which we know fits well with what we observe of its efflcacy and its failures in the treatment of srphilis. It is antidotal to the virus, and so long as present it prevents its manifestations of activity. In some cases, but by no means in the majority, it probably kills it outright. The more usual result is a repression of vital activity in the virus, which lasts as long as the drug is used. This repression, if continued for long periods, would appenr to amount to a very important modification of power, for 1 believe that if the secondary phenomena be kept in abeyance for many months, their subsequent development, if then permitted, will never be severe. If continued long enough it will wholly prevent the secondary stage, and yet I fear it is true that even in these the patient may be liable to tertinry affections.

If it be rejoined that no remedy can claim to be antidotal or specific respecting which it is admitted that it does not prevent tertiary sequele, a reply is yet possible. There is a sense in which, without any hair-splitting, tertiary symptoms may be said not to be syphilis at all. There is neither proof nor probability that the microbe or virus is present in their lesions. They do not develop symmetrically, and they are not contagious; they are due to processes of inflammation occurring in tissues which have formerly been under the influence of sypliilis, and hare been modified by it. If this be their true position, it will easily be seen that no antidotal treatment directed to the killing of the microbe can prevent them, unless it is commenced before the system has been contaminated. If we wait till the sore is well developed, the patient feverish, and the eruption on the eve of appearance, we have waited until the patient has had syphilis through him, and though we may then proceed to cure the disense by killing the poison, it is too late to prevent its remote effects. In saying this, do not let me be understood to say that the use of mercury late makes no difference as to proclivity to tertiary symptoms. On the contrary I believe, although it is impossible to prove it, that it does make them both less common and of milder type.

The practical questions which come, then, before the surgeon are these-In what manner and at what stage ought mercury to be given so as best to secure its antidotal efficacy?

The verdict that mercury given in short courses is not preventive of the development of syphilis has been recorded in unmis takable terms by the surgeons of the past generation. Mr. Judd, indeed, whose reports are full of interest, and contain proof alike of ability and of candour, thought that such courses favoured the absorption of the rirus, and made the disease eventually more severe. His courses were, however, of a fortnight, a month, or six weeks at the most, and were always attended by free ptyalism. The modern introduction of the small-dose system, with the avoidance of ptyalism, makes it necessary that we should investignte the whole question anew. I lo not suppose that there is much difference, as to the special preparation of mercury which is employed, though it will not do to take this for granted. Some of the records of M. Diday as to his failures to prevent symptoms would add to the suspicion that the iodide of mercury, as employed by him, is less efficient than the mercury only, in the form of grey powder. The great point is that a preparation should be used which can be pushed without producing symptoms which necessitate its temporary discontinuance. It $\mathrm{s}$ efficacy may be taken as proved by the prompt disappearance of the primary induration. The dose which is efficient to this result will, if steadily persevered with, probably be efficient in preventing the development of other symptoms.

The question arises, I think, naturally, at this point of our inquiry as to whether it may not be advisable in the future to attempt the abortion of the primary stage itself. I am not aware that any large amount of evidence is in existence as to the possibility of preventing the development of induration in a chancre by using mercury before it occurs. Ever since the recognition of the fact that some chancres are not infecting, and that the phenomenon of induration is the most valuable one by which to diagnose the true or infective chancre, we have been in the habit of waiting till the character of the sore declares itself before beginning to use the specific. Many, indeed, especially those of the French school, have advocated waiting till constitutional symptoms in the form of eruption occur. Our forefathers, we well know, did not so wait. For them a venereal sore was a chancre, and they poured in mercury as soon as the patient presented himself, and often within a week or two of the contagion. It may have been that in many cases they succeeded in aborting syphilis as a whole, and in preventing alike the primary and secondary stages. It is to be feared, however, that their success was but too often prevented by the manner in which they prescribed the antidote. They were accustomed to give large doses during short periods, and were constantly obliged, hy the occurrence of pt yalism, to interrupt the treatment. Indeed, as a rule, a short treatment was all that was contemplated, and the production of free ptyalism was regarded as essential. As I have already suggested mercury may sometimes, when given in this war, possibly prove an abortive treatment-that is, it may kill the virus. Facts, however, would seem rather to point to the conclusion that it only temporarily suspends its activity, and that in many cases a severe outbreak follows soon after its suspension. It is otherwise, I think, when small doses are long continued.

1 wish to avoid giving any exaggerated impression of the extent and kind of evidence upon which my statements are based. It is not my intention to produce before you any statistical evidence, nor even to quote individual cases. To do so would be very easy, for I hold in my hand a large number of extracts from my notebooks which bear upon the matter. To read them to you would however be very monotonous, and I think unprofitable. They are for the most part repetitions of the statement that the patient came under my care with a well-indurated chancre, that I advised a long course of small doses of mercury, that the induration melted away, and that nothing else ever followed. There is a weak point in many, but by no means in all, and it is this, that I have no record as to the patients beyond the first six months or so. My practice has for many years, in respect to primary syphilis, been solely in private, and it is of course not practicable to compel patients to come and report after they believe themselves well. I feel sure, however, that this negation of evidence is in itself of considerable strength. For long, as I have said, I have been in the habit of holding out hopes of immunity, if the remedy were persevered with, and I assume that if my foretellings proved fallacious, I should in the majority of cases hear of it. On the contrary, so far as my own observation of primary syphilis has for many years past been concerned, I should certainly never have discovered that an eruption on the skin was a usual part of the malady. I have of course seen plenty of secondary eruptions in those who had not been under treatment, but in those whom I had myself prescribed for in the primary stage scarcely any. I could count on my fingers the number of cases in which during the last five years I have watched the patient from his primary sore through a well-marked syphilitic eruption on the skin. A few I have seen, probably because not sufficient mercury was given, and more in which some very slight and transitory eruption showed that the poison, though restrained, was struggling to show its powers. Of really troublesome eruptions, such as are common enough when mercury has not been used, I may say confidently that $I$ have seen none.

I must admit that the gross total of cases of primary syphilis which have been under my care has not been so large as that which falls to the share of specialists, particularly those holding hospital appointments. More patients come to me in the secondary, or later stages, than in the primary. Still, my experience has been considerable, and justifies, I think, the general statements which I have ventured to make to you this evening. It is to be clearly understond that $I$ have been spenking only of cases in which the induration was characteristic, and in which an interral of from five to seven weeks had occurred since the exposure I have never allowed myself to diagnose a sore as infectious, or to begin mercury, except under these conditions.

There is another class of cases which bear testimony which is, 1 think, very valuable as regards the antidotal efficacy of mercury. I allude to those in which the patient comes under care with his rash fully out, and having as yet had no treatment. The possibility of aborting the rest of the malady in these is less certin, yet I think we may generally expect it with much confi- 
dence. If such patients will take mercury their symptoms will disappear, and if they will continue it there will be no relapses.

In conclusion, I may express my hope that it will have been clear to all that my object in this paper has not been to claim credit for any particular method of treatment, far less to make boast of personal success. My wish has been to draw attention to a clinical fact which, although hitherto much ignored, or even denied, must have been for long more or less under the cognisance of all engnged in the treatment of syphilis according to modern rules. The fact to which I refer is that the early use of mercury does not only greatly shorten the duration of the primary plenomena, but that it also much modifies, and in many instances entirely prevents, those of the secondary one. I have indeed rentured to assert that, when circumstances favour, the febrile stage of the exanthem, syphilis may be rendered wholly abortire. If we can accept this proposition, I feel sure that we shall have gained a step in the orderliness of our future work, and in reference to this the following problems seem to lie before us.

What plan of treatment is most successful in suppressing the febrile or secondary stage?

Does the suppressing of this stage tend to prevent what are called reminders, or those minor, and for the most part local, symptoms which often intervene between the febrile stage and tertiary phenomena?

Are those in whom the febrile stage has been aborted by artificial means more or less than others liable to tertiary phenomena?

Is it possible by anticipatory treatment to prevent or abort the phenomena of the primary stage; and, if this be done, what is the influence upon the further course of the disease?

It has been well said that all men use syllogisms, whilst but few have studied logic; and in like manner $I$ may remark that most of us have been practising more or less completely the abortive treatment of syphilis, though without giving it that name.

\section{CLINICAL MEMORANDA.}

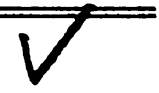

\section{TUMOUR OF THE INTESTINE: SYMPTOMS SIMULATING BILIARY COLIC.}

Colonet M., aged 45, who had lived in India for some twenty years, was scized about 2 A.Mr. on 4th June with agonising pain referred to the right side of his abdomen. An injection of morphine gave relief. But in the course of the following night the pain returned with even greater intensity, so much so, that recourse was had to chloroform inhalation. The case seemed obviously to be one of gall-stone colic, and directions were given to wash the frees through muslin. On the 6th June the patient passed what he thought was a " piece of flesh," but which was a lymphoma of nearly square outline, measuring about one inch and a-half along each side, and a quarter of an inch in thickness. This is not the place for a description of the tumour. As the textbooks give no warning of this source of error in the diagnosis of biliary colic, it seems wortl while to place the case on record. Regarding the patient's subsequent history, a dull pain in the abdomen, chiefly on the right side, continued for some days, at the end of which he regained his usual excellent health. There has been no recurrence of symptoms up to date.

Henrietta Street, W.

J. LEWTA8, M.D.Loud.

\section{PUERPERAL APHASIA.}

Tre interesting remarks made by Dr. Bateman on the above subject in the JournaL of February 4th lead me to record the following case.

In April, 1886, I was called to see, in consultation with Dr. Maguire, of Chesterton, Mrs. B., aged 35, who had given birth to her tenth child ten days before. For some time she had suffered from anæmia with a hæmic murmur, but had improved in health before her confinement, which was quite natural; and she went on perfectly. well, suckling her child until the tenth day, when she sat up in a chair for the first time. She was suddenly taken spee chless and helpless, the right side being completely paralysed. In this condition 1 found her. Like Dr. Leith Napier in his case, quoted by Dr. Bateman, we attributed the symptoms to occlusion, by embolism, of the left cerebral artery. Mrs. B. was perfectly conscious, and understood everything said to her. There was no increased flow of milk; in fact it went the same night after the

attack. The use of the arm and leg was soon regained, so that in five weeks she was enabled to walk about the house, and in five months to walk a distance of some miles. In June, 1887, I saw her at Llandudno with Dr. Dalton. We then detected no hæmic murmur. IIer general henlth had grently improved, but her speech remained very defective: and, as it lias not improved much, if at all, since then, 1 fear it never will.

Newcastle-under-Lyme.

Charles Orton.

\section{REPORT S}

HOSPITAL AND SURGICAL PRACTICE IN THE HOSPITALS AND ASYLUMS OF

GREAT BRITAIN, IRELAND, AND THE COLONIES.

\section{ALBAFY GENERAL HOSPITAL, GRAHAMSTOYN,} SOUTII AFRICA.

A CASE OF HYSTERECTOMY.

\section{(By J. B. Greathead, M.B.Edin., M.R.C.S.Eng., Largeon to the} Hospital.)

J. A., aged 33, a spinster, was first seen on September 5th, 1886. She had had persistent metrorrhagia and menorrhagia for twelve months, and had become very anæmic. The abdominal tumour had grown more rapidly for three months, and, from its size and weight, caused much inconvenience. The cervix was obliterated ; and the os externum, somewhat patulous, was pressed forwards against the upper edge of the pubes. The sound could not be passed, but with the aid of a gum elastic catheter the uterine cavity was found to extend eight inches upwards and forwards in front of the main portion of the tumour.

On September 22nd, 1886, chloroform (with ether at intervals) having been administered, a preliminary incision four inches long between the pubes and umbilicus was made. When the diagnosis had been satisfactorily confirmed, the abdominal incision was gradually enlarged until it extended from the pubes to within an inch of the ensiform cartilage. Only then could the tumour with difficulty be brought through the opening. An elastic tourniquet was placed round the uterus just where the vaginal walls joined it. With a large trocar and cannula a pint and a half of black fluid blood was drawn off from the highest part of the tumour. The broad ligaments were next tied in sections and divided as low as possible; but, in order to reach the lowest portions, it was found necessary to cut into the uterus and remove a large portion of the tumour. In this way the pedicle was more readily handled. The uterine arteries were tied with silk and divided. The uterus was next transfixed just above the junction with the raginal walls, and tied in two portions with strong silk ligatures. The remainder of the uterus was now amputated half an inch above the last ligatures, a small posterior flap of uterine tissue and peritoneum being reserved for the closing in of the end of the stump (pedicle). After all hæmorrhage was well controlled and the tourniquet removed, the flap was brought forward and firmly sutured (with five silk sutures) to the anterior elge of the uterine wound. The loose peritoneum was gathered in with a continuous catgut suture, and closed over a neat stump. The abdominal cavity having been cleansed with warm water and all tluid sopped up from the pelvic cavities, the abdominal wound was closely sutured with silver wire in the customary way. A dressing of lint and carbolic oil (1 to 20), with a liberal supply of cotton wadding, was used.

On September 24th the evening temperature was $99.6^{\circ} \mathrm{F}$., the pulse 120. On September 26th the wound was entirely healed; the evening temperature was $99.6^{\circ} \mathrm{F}$. On September 28 th the evening temperature was $101.6^{\circ} \mathrm{F}$. On October 3rd the evening temperature was $102^{\circ} \mathrm{F}$., and the pulse 114 . Flatulence caused pain, and was relieved by an enemu of soap and water. On October 4 th the evening temperature was $101.6^{\circ} \mathrm{F}$. After this date the temperature gradully became normal, and on October 13th the patient was considered convalescent, and allowed to recline in a semi-recumbent posture. On October 28th and 29th she menstruated, with all her usual symptoms. On November 17th to 19 th she menstruated again, with usual sensations. The patient wrote saying that she had again menstruated on December 8th and 9th. She had been in the habit of menstruating every three weeks before this illness. 